\title{
A New Single-Stage Multilevel Type Full-Bridge Converter Applied to closed loop condition
}

\author{
K Vamshi Krishna Varma*1, Vemana Arun Sai*2, \\ Mohammed Wajidunnisa* ${ }^{3}$, Nasina Jyothirmayi* ${ }^{4}$, S.Sridhar ${ }^{5}$ \\ Asst professor in EEE department, Training \& placement officer in Geethanjali Institute of Science \& \\ Technology Gangavaram (Nellore Dist) A.P, India \\ Department of Electronics and commmunication Engineering, Geethanjali Institute of Science \& \\ TechnologyGangavaram(Nellore Dist) A.P, India. \\ Department of Electronics and commmunication Engineering, Geethanjali Institute of Science \& \\ TechnologyGangavaram(Nellore Dist) A.P, India. \\ Department of Electronics and commmunication Engineering, Geethanjali Institute of Science \& \\ TechnologyGangavaram(Nellore Dist) A.P, India. \\ Assoc professor in EEE department, H.O.D Of EEE in Geethanjali Institute of Science \& Technology \\ Gangavaram (Nellore Dist) A.P, India
}

\begin{abstract}
Switch Mode rectifiers for power-factor correction have gained considerable attention, due to the increasing demand for improved power quality. A new three-phase single-stage rectifier with Brushless DC motor is proposed in this paper. Each converter operates in the continuous conduction mode (CCM), which allows a high power factor and a small EMI filter. The outstanding features of the proposed rectifier are that it can produce input currents that do not have dead band regions and an output current that can be continuous when the converter is operating from maximum load to at least half of the load. Here we proposed full bridge converter with machine load condition system is validated through MATLAB/SIMULINK Platform.

Keywords: $A C-D C$ power conversion, single-stage power factor correction (SSPFC), three-level converters, DC motor, Brushless DC motor.
\end{abstract}

\section{INTRODUCTION}

Electric Power quality is a term which has captured increasing attention in power engineering in the recent years, The measure of power quality depends upon the needs of the equipment that is being supplied. The low power factor and high pulsating current from the AC mains are the main disadvantages of the diode rectifier and phase controlled rectifier. A three phase ac-dc power conversion with input power factor correction (PFC) and transformer isolation is typically done using a six-switch front-end ac-dc converter to do the PFC and a four-switch full-bridge converter to do the dc-dc conversion [1].

This approach, however, is expensive and complicated as it needs ten active switches along with associated gate drive and control circuitry. Moreover, the converter must be operated with sophisticated control methods that require the sensing of certain key parameters such as the input currents and voltages; this is particularly true if online pulse width modulation (PWM) techniques are used. Researchers have tried to reduce the cost and complexity of the standard converter by modifying the ac-dc front end converters. Proposed alternatives have included: 1) using three separate ac-dc boost converter modules [2]; 2) using a reduced switch ac-dc converter [3]; and 3) using a single-switch boost converter [4]. Two separate switch-mode converters are still needed, however, to perform three-phase ac-dc power conversion with transformer isolation. Researchers have tried to further reduce the cost and complexity associated with single-phase and three-phase ac-dc power conversion and PFC by proposing single-stage converters that integrate the functions of PFC and isolated dc-dc conversion in a single power converter. Previously proposed three-phase single-stage ac-dc converters as shown in Fig.1, however, have at least one of the following drawbacks that have limited their widespread use.

1) They are implemented with three separate ac-dc single stage modules.

2) Converter components are exposed to very dc bus high voltages so that switches and bulk capacitors with very high voltage ratings are required.

3) Input currents are distorted and contain a significant amount of low-frequency harmonics because the converter has difficulty performing PFC and dc-dc conversion simultaneously.

4) Converter must be controlled using very sophisticated techniques and/or nonstandard techniques. This is particularly of resonant type converter that need variable switching frequency control methods to operate.

5) Output inductor must be very low, which makes the output current to be discontinuous. This results in a very high output ripple so that secondary diodes with high peak current ratings and large output capacitors to filter the ripple are needed. This paper presents a new three-phase, single-stage rectifier that does not have any of 
these drawbacks. In this paper, the operation of the new converter is explained, its features and design are discussed in results, and converter is applied to drive to check the performance of drive.

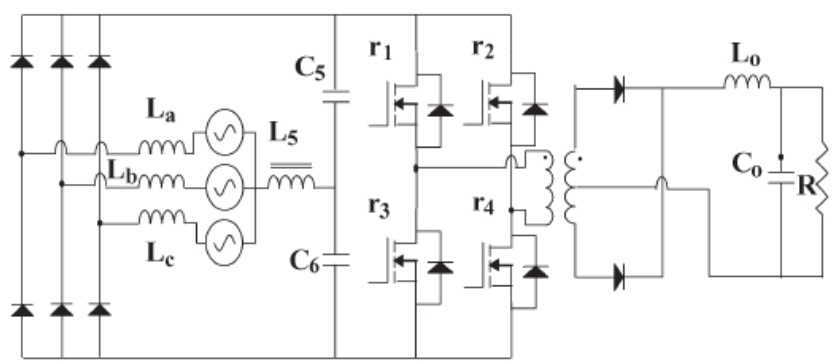

Fig.1 Previous proposed AC/DC Single Stage Converter

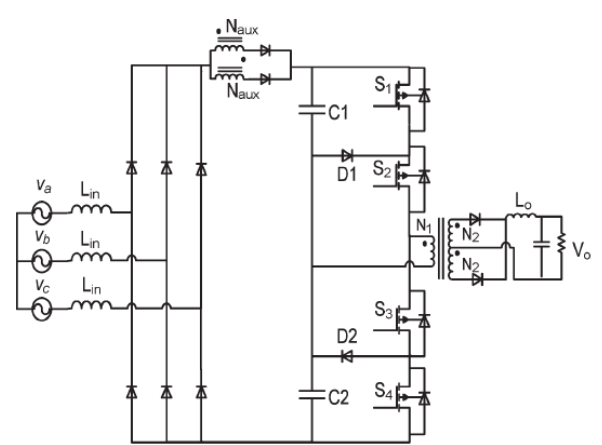

Fig.2 Newly Proposed AC/DC Single Stage Converter

II. CONVERTer Operating Principle

The proposed converter and its key waveforms are shown in Figs. 2 and 3. The basic principle behind the proposed converter is that it used auxiliary windings that are taken from the converter transformer to cancel the dc bus capacitor voltage so that the voltage that appears across the diode bridge output is zero. This voltage cancellation occurs whenever there is voltage across the main transformer winding and current in the input inductors rises when it does. When there is no voltage across the main transformer primary winding, the total voltage across the dc bus capacitors appears at the output of the diode bridge; since this voltage is greater than the input voltage, the input currents falls.

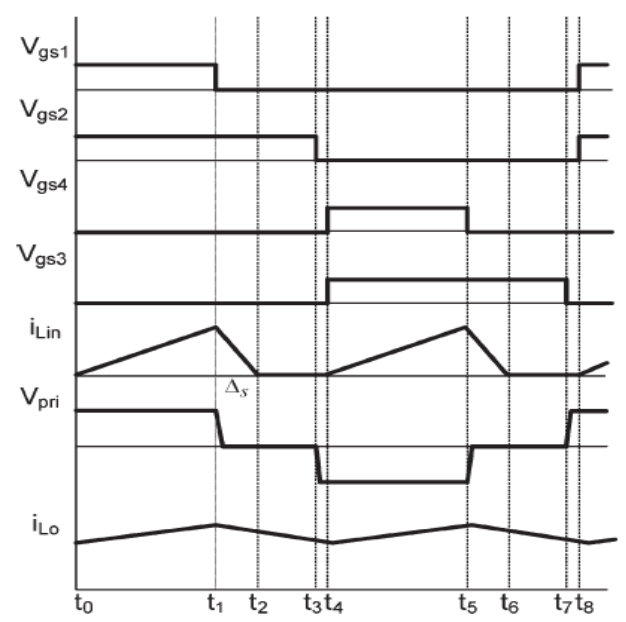

Fig. 3. Typical waveforms describing the modes of operation.

To simplify the analysis, the following assumptions are made, If the input currents are discontinuous, they will be naturally nearly sinusoidal (when filtered) and in phase with the input voltages. 1) The input voltage value can be considered as constant within a switching period as the period of the three-phase voltage supply is much longer than the switching period;

2) All devices are ideal; 3) The currents in inductors $L a=L b=L c=L$ in are $i L a, i L b, i L c$ and have the same amplitude; 4) The dc bus voltage has no ripple. 
The equivalent circuit in each stage is shown in Fig. 4. The converter goes through the following modes of operation in a half switching cycle.

Mode $1(\mathrm{t} 0<\mathrm{t}<\mathrm{t} 1)$ :

During this interval, switches $S 1$ and $S 2$ are ON. The switches remain ON for a period given by $D / 2 f s w$. In this mode, energy from the dc link capacitor $C 1$ flows to the output load. Due to magnetic coupling, a voltage appears across one of the auxiliary windings and cancels the total dc bus capacitor voltage; the voltage at the diode bridge output is zero, and the input currents rise. Due to the high switching frequency, the supply voltage is assumed constant within a switching cycle. In this mode, the three-phase input current equations are as follows:

$$
\begin{gathered}
v_{a}=L_{a} \frac{d i_{L a}}{d t} \\
v_{b}=L_{b} \frac{d i_{L b}}{d t} \\
v_{c}=L_{c} \frac{d i_{L c}}{d t} \\
i_{L a}+i_{L b}+i_{L c}=0 \\
v_{a}+v_{b}+v_{c}=0 .
\end{gathered}
$$

As it can be seen from (1), the equations that describe the relation between the current and voltage of input currents $i L a, i L b$, and $i L c$ are the same, but with different notation. Therefore, instead of using terms with subscripts $\mathrm{a}, \mathrm{b}$, and $\mathrm{c}$ in this paper, a general notation $\rightarrow$ is defined so that only one equation is written instead of three equations. Equation (1) can thus be rewritten as

$$
\vec{v}=L_{\mathrm{in}} \frac{d \overrightarrow{\nu_{L_{\mathrm{in}}}}}{d t}
$$

The auxiliary inductor current increases during this mode, and the following expression can be written:

$$
\overrightarrow{\iota_{L_{\mathrm{in}}, k}}(t)=\frac{\left|\overrightarrow{v_{k}}\right|}{L_{\mathrm{in}}} \cdot t
$$

At the end of Mode I, the current in the auxiliary inductor $L$ in, during the kth interval is

$$
\vec{\imath}_{L_{\text {in }}, k, \max }=\frac{|\overrightarrow{v k}|}{L_{\text {in }}} \cdot \frac{D}{2 f} \text { sw }
$$

where $v k$ is the average value of the supply voltage in the interval $\mathrm{k}, \mathrm{D}$ is the duty cycle, and $f s w$ is the switching frequency. Since the converter operates with a steady-state duty cycle D that is constant throughout the line cycle, the peak value of an input inductor current at the end of this mode is dependent only on the supply voltage.

The output inductor current can be expressed as

$$
i_{L o}(t)=\frac{\frac{V_{\mathrm{bus}}}{2 N}-V_{L}}{L_{o}} \cdot t
$$


A New Single-Stage Multilevel Type Full-Bridge Converter Applied to closed loop condition

where $V$ bus is the average dc-link voltage and $V L$ is the average load voltage and $\mathrm{N}$ is the transformer ratio between input and output $(N=n 1 / n 2)$. If it is assumed that the output inductor current is continuous, then the following expression for peak to peak ripple can be derived:

$$
\Delta i_{L o}=\frac{\frac{V_{\mathrm{bus}}}{2 N}-V_{L}}{L_{o}} \cdot \frac{D}{2 f}{ }_{s w}
$$

(6)

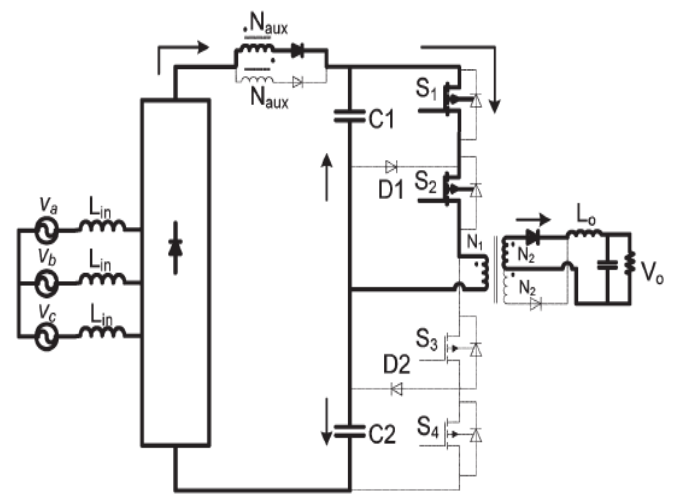

(a )Mode $1(\mathrm{t} 0<\mathrm{t}<\mathrm{t} 1)$

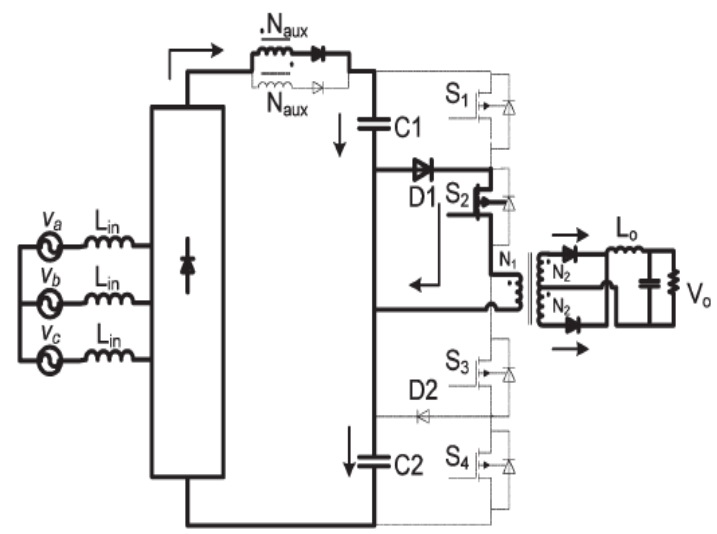

(b) Mode $2(t 1<t<t 2)$.

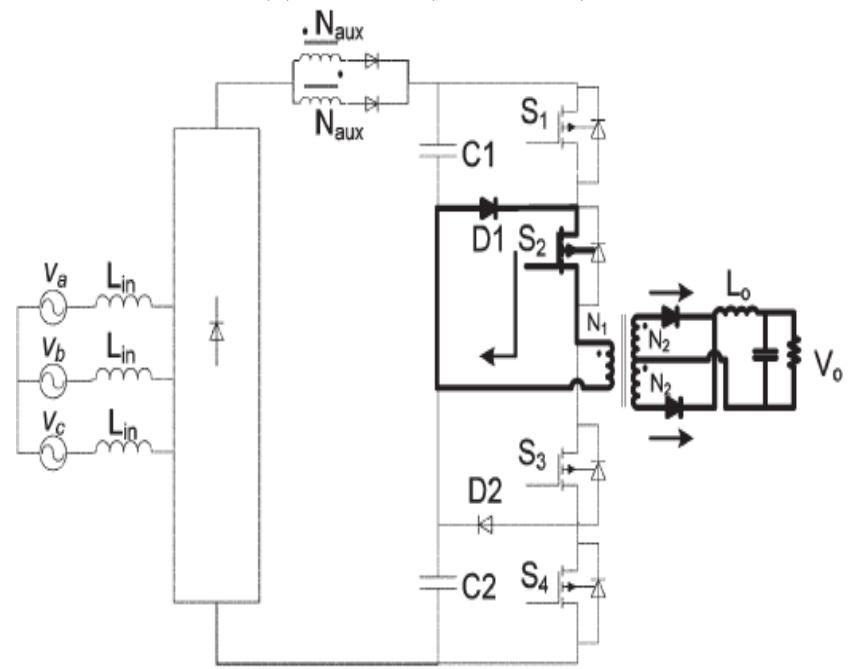

(c) Mode $3(t 2<t<t 3)$.

www.iosrjournals.org

27 | Page 


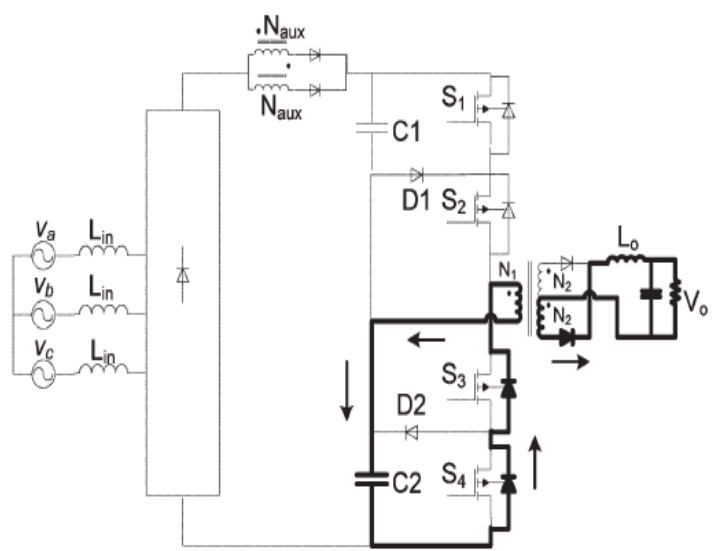

(d) Mode $4(t 3<t<t 4)$.

Fig. 4. Modes of operation

Mode $2(\mathrm{t} 1<\mathrm{t}<\mathrm{t} 2)$ :

In this mode, $\mathrm{S} 1$ is $\mathrm{OFF}$, and $\mathrm{S} 2$ remains $\mathrm{ON}$. The energy stored in the auxiliary inductor during the previous mode is completely transferred into the dc link capacitor. The amount of stored energy in the auxiliary inductor depends upon the rectified supply voltage. This mode ends when the auxiliary inductor current reaches zero. Also, during this mode, the load inductor current freewheels in the secondary of the transformer. The voltage across the auxiliary inductors in Mode II is $V k \mid$ - Vbus, thus, the auxiliary current expression is as follows:

$$
\begin{aligned}
\frac{d \overrightarrow{\imath_{L_{\mathrm{in}}}}}{d t} & =\frac{\left|\overrightarrow{V_{k}}\right|-V_{\mathrm{bus}}}{L_{\text {in }}} \\
\vec{\imath}_{L_{\mathrm{in}}, k}(t) & =i_{L_{\mathrm{in}}, k, \max }-\frac{V_{\mathrm{bus}}-\left|\overrightarrow{V_{k}}\right|}{L_{\mathrm{in}}} \cdot t .
\end{aligned}
$$

This mode ends when the auxiliary inductor current reaches zero. This mode lasts for $\Delta s, k / 2 f s w$ amount of time; using (4), the following expression can be found:

$$
\vec{\Delta}_{s, k}=\frac{\left|\overrightarrow{V_{k}}\right|}{V_{\text {bus }}-\left|\overrightarrow{V_{k}}\right|} D
$$

where $\Delta s, k$ is the normalized period of Mode II. Equation (8) shows that the duration of this mode is time varying along one ac line period. In order to ensure a discontinuous input current, the normalized period $\Delta s, k$ must satisfy the expression $D+\Delta s, k<1$ for any interval $\mathrm{k}$ and any load conditions. Using (8), this constraint can be written as

$$
V_{\text {bus }}>\frac{\left|\overrightarrow{V_{k}}\right|}{1-D}
$$

On the other hand, the load inductor current freewheels in the secondary of the transformer, which defines a voltage across the load filter inductor equal to $-V L$; therefore, the load inductor current is given by

$$
\begin{gathered}
i_{L o}(t)=i_{L o, \max }-\frac{V_{L}}{L_{o}} t \\
\Delta i_{L o}=\frac{V_{L}}{L_{o}} \frac{1-D}{2 f_{s w}} .
\end{gathered}
$$


Consequently, the following expression can be derived from (6) and (11)

$$
V_{o}=\frac{V_{\text {bus }}}{2 N} D
$$

Mode $3(\mathrm{t} 2<\mathrm{t}<\mathrm{t} 3)$ :

In this mode, the primary current of the main transformer circulates through D1 and S2, and the output inductor current freewheels in the secondary. There is no energy transferred to the dc bus capacitors.

Mode $4(\mathrm{t} 3<\mathrm{t}<\mathrm{t} 4)$ :

In this mode, S1 and S2 are OFF, and the primary current of the transformer charges $\mathrm{C} 2$ through the body diodes of S3 and S4. Switches S3 and S4 are switched ON at the end of this mode and the half switching cycle ends. For the remainder of the switching cycle, the converter goes through Modes 1 to 4, but with S3 and S4 ON instead of S1 and S2.

Mode $5(\mathrm{t} 4<\mathrm{t}<\mathrm{t} 5)$ : In this mode, S3 and S4 are ON; a symmetrical period begins. In this mode, energy flows from the capacitor $\mathrm{C} 2$ into the load. The voltage across the auxiliary inductors becomes only the rectified supply voltage of each phase, and the current flowing through each inductor increases.

Mode $6(\mathrm{t} 5<\mathrm{t}<\mathrm{t} 6)$ : In this mode, S3 is ON, and S4 is OFF. The energy stored in the auxiliary inductors during the previous mode is completely transferred into the dc-link capacitor.

Mode $7(\mathrm{t} 6<\mathrm{t}<\mathrm{t} 7)$ : In this mode, S4 is OFF, and the primary current of the main transformer circulates through the diode D2 and S3. The output inductor current also freewheels in the secondary of the transformer during this mode.

Mode $8(\mathrm{t} 7<\mathrm{t}<\mathrm{t} 8)$ : In this mode, S3 and S4 are OFF, and the primary current of the transformer charges the capacitor C1 through the body diodes of S1 and S2. Switches S1 and S2 are switched on at the end of this mode. Output voltage regulation can be done by standard control methods that control duty cycle D. Duty cycle, D in (4), is defined as the time when S1 and S2 are both ON during the first half cycle or when S3 and S4 are both ON during the second half cycle. These two cases correspond to energy transfer modes of operation. Any control method that can be used to regulate a two-level full-bridge converter by controlling D can be used to regulate the proposed converter; the only difference is how the gating signals are implemented. For example, the control for the proposed converter can be implemented with a conventional phase-shift PWM controller, and some logic can be added to the output of the controller to generate the appropriate gating signals. Since the converter is a multilevel converter, it should be implemented with some sort of capacitor voltage balancing to ensure the voltage across each bus capacitor is the same.

Various such techniques have been proposed in the literature, including techniques that sense the capacitor voltages and adjust the duty cycle of the converter switches appropriately.

\section{Matlab/SimulinK Modelling AND Simulation ReSUlts}

Here the simulation is carried out by two cases 1. Proposed Full Bridge Multilevel Converter 2. Proposed Full Bridge Multilevel Converter with DC Machine Loading.

Case 1: Proposed Full Bridge Multilevel Converter

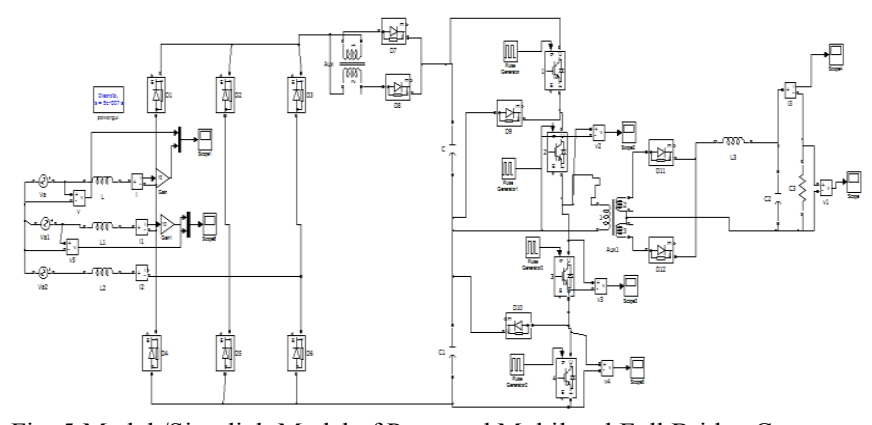

Fig. 5 Matlab/Simulink Model of Proposed Multilevel Full Bridge Converter

As above fig. 5 shows the Matlab/Simulink Model of Proposed Multilevel Full Bridge Converter. 


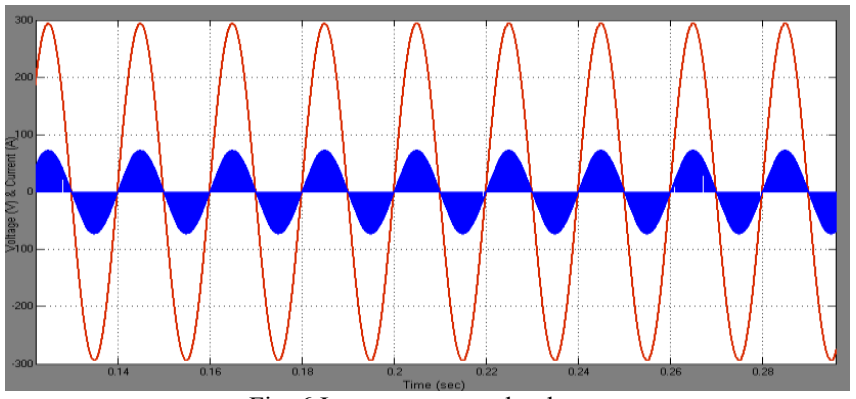

Fig. 6 Input current and voltage

As above Fig. 6 shows the input current and voltage, it represents the source side power factor of proposed converter.

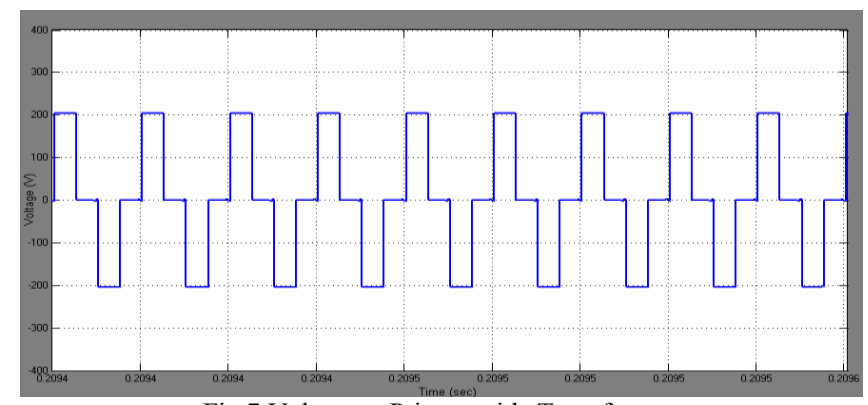

Fig.7 Voltage at Primary side Transformer

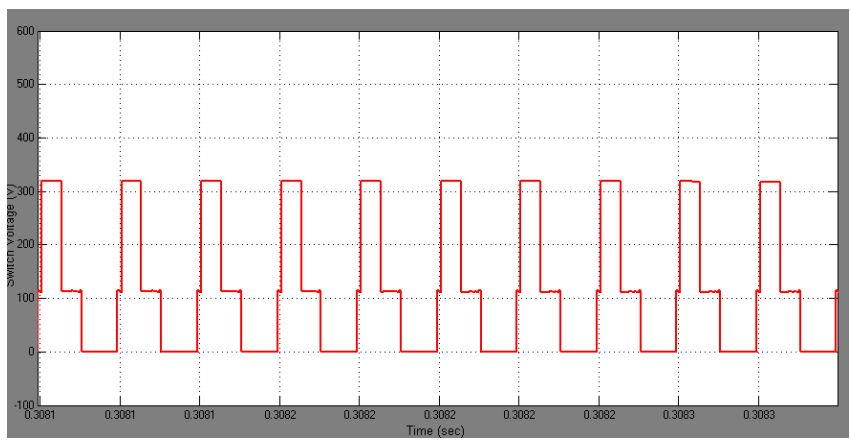

Fig. 8 Voltage Across switch

As above Fig. 8 shows the voltage across the switch in proposed multilevel full bridge converter.

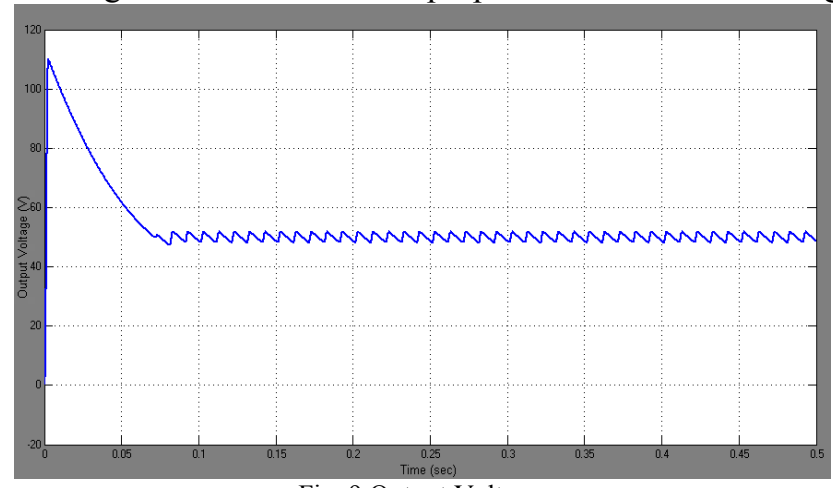

Fig. 9 Output Voltage

As above fig. 9 shows the Output Voltage of Proposed Multilevel Full Bridge Converter. Here we get output at steady state after the $0.1 \mathrm{sec}$.

Case 2: Proposed Full Bridge Multilevel Converter with Machine Loading 


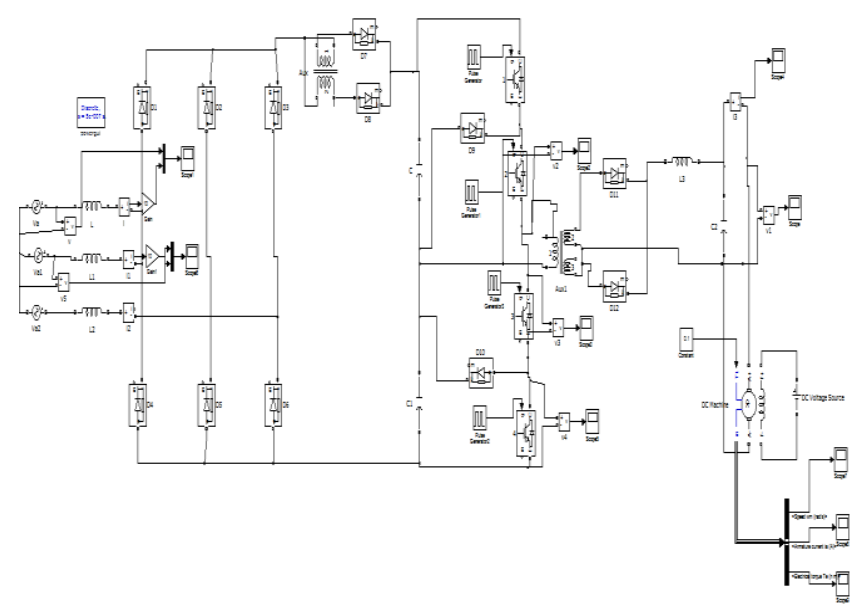

Fig. 10 Matlab/Simulink Model of Proposed Multilevel Full Bridge Converter with machine load

As above fig. 10 shows the Matlab/Simulink Model of Proposed Multilevel Full Bridge Converter with DC machine loading.
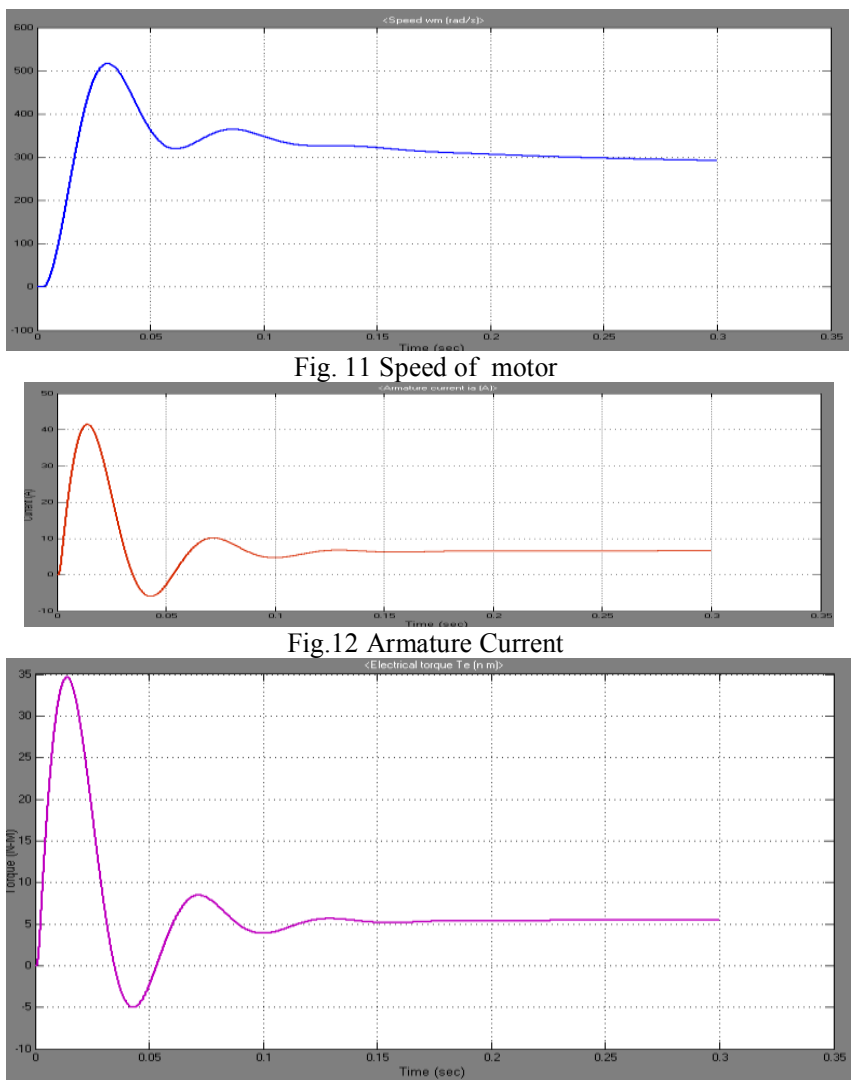

Fig.13 Electromagnetic Torque

As fig shows the performance characteristics of DC motor with proposed multilevel full bridge converter.

Case 3:-proposed Full Bridge Multilevel Converter with closed loop condition

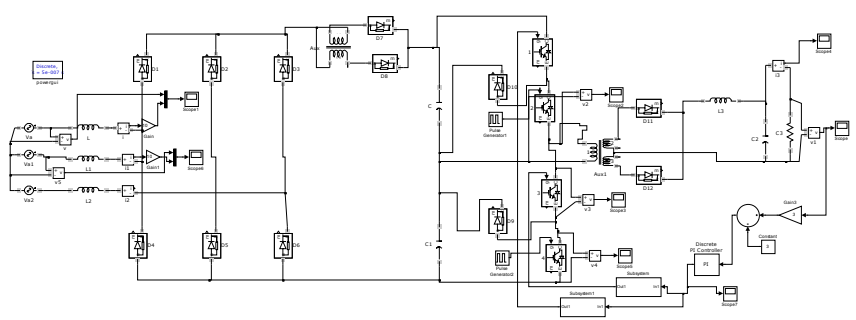

Fig14 Matlab/Simulink Model of Proposed Multilevel Full Bridge Converter with closed loop 

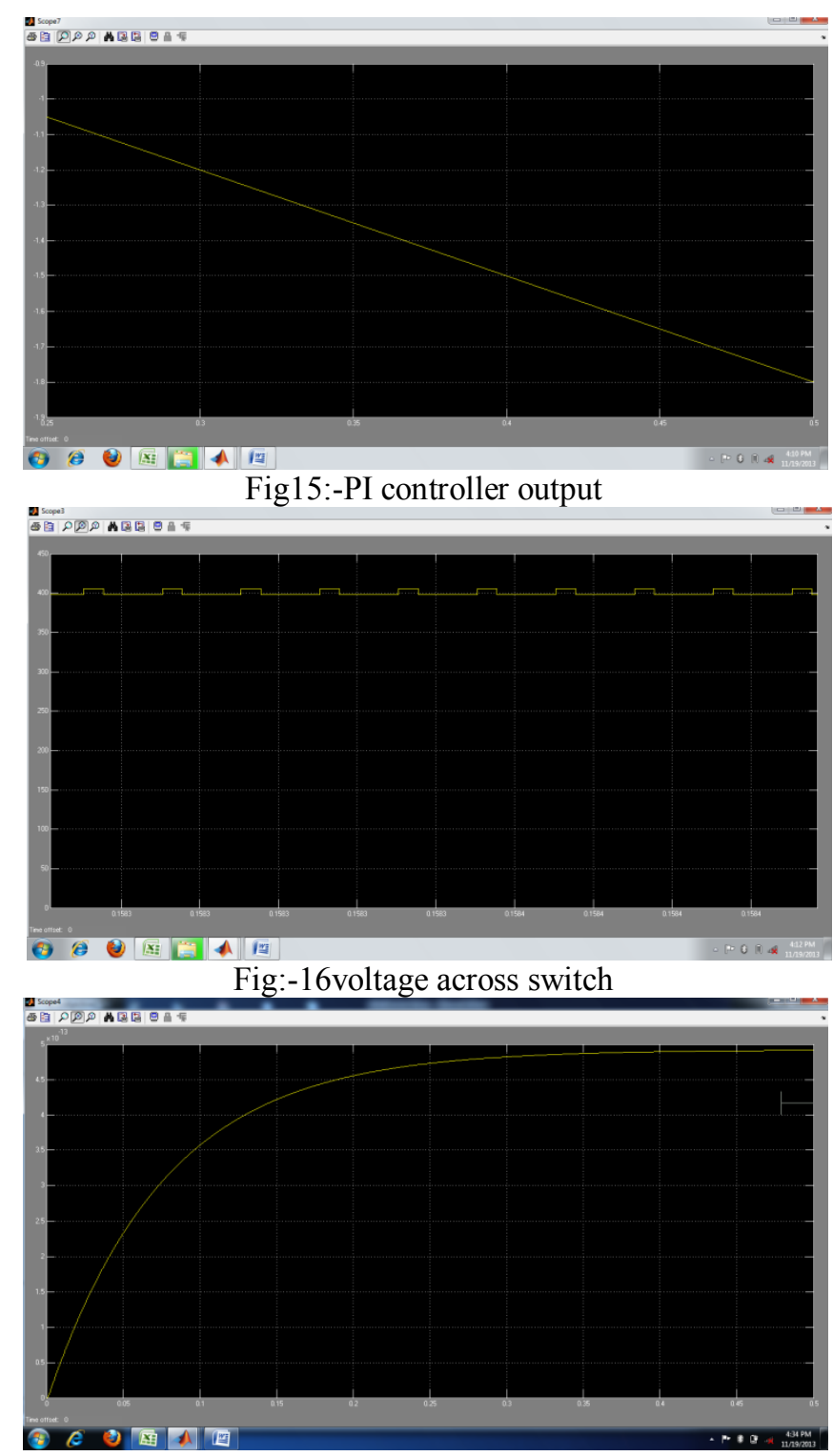

Fig17:-Current across inductor

\section{CONClusion}

A three-phase, three-level, single-stage power-factor corrected ac/dc converter that operates with a single controller to regulate the output voltage was presented in this paper. The proposed converter has the following features. Proposed converter has an auxiliary circuit that can cancel the capacitor voltage in which way the input inductor acts as a boost inductor to have a single-stage PFC. Proposed converter can operate with lower peak voltage stresses across the switches and the dc bus capacitors as it is a three-level converter. This allows for greater flexibility in the design of the converter and ultimately improved performance, proposed converter is applied to closed loop condition.

\section{References}

[1] P. D. Ziogas, Y. Kang, and V. R. Stefanovic, "PWM control techniques for rectifier filter minimization," IEEE Trans. Ind. Appl., vol. IA-21, no. 5, pp. 1206-1214, Sep. 1985.

[2] G. Spiazzi and F. C. Lee, "Implementation of single-phase boost power factor correction circuits in three-phase applications," IEEE Trans. Ind. Electron., vol. 44, no. 3, pp. 365-371, Jun. 1997.

[3] B. Lin and D. P. Wu, "Implementation of three-phase power factor correction circuit with less power switches and current sensors," IEEE Trans. Aerosp. Electron. Syst., vol. 34, no. 2, pp. 64-670, Apr. 1998.

[4] A. R. Prasad, P. D. Ziogas, and S. Manias, "An active power factor correction technique for three-phase diode rectifiers," in $I E E E$ Power Electron. Spec. Conf. Rec., 1989, pp. 58-66.

[5] J. M. Kwon, W. Y. Choi, and B. H. Kwon, "Single-stage quasi-resonant flyback converter for a cost-effective PDP sustain power module," IEEE Trans. Ind. Electron., vol. 58, no. 6, pp. 2372-2377, Jun. 2011.

[6] H. S. Ribeiro and B. V. Borges, "Analysis and design of a high efficiency full-bridge single-stage converter with reduced auxiliary components," IEEE Trans. Power Electron., vol. 25, no. 7, pp. 1850-1862, Jul. 2010. 
[7] H. L. Cheng, Y. C. Hsieh, and C. S. Lin, "A novel single-stage high-power factor ac/dc converter featuring high circuit efficiency," IEEE Trans. Ind. Electron., vol. 58, no. 2, pp. 524-532, Feb. 2011.

[8] S. K. Ki and D. D.-C. Lu, "Implementation of an efficient transformer less single-stage single-switch ac/dc converter," IEEE Trans. Ind. Electron., vol. 57, no. 12, pp. 4095-4105, Dec. 2010.

[9] H. Ma, Y. Ji, and Y. Xu, "Design and analysis of single-stage power factor correction converter with a feedback winding," IEEE Trans. Power Electron., vol. 25, no. 6, pp. 1460-1470, Jun. 2010.

[10] H. J. Chiu, Y. K. Lo, H. C. Lee, S. J. Cheng, Y. C. Yan, C. Y. Lin, T. H. Wang, and S. C. Mou, "A single-stage soft-switching flyback converter for power-factor-correction applications," IEEE Trans. Ind. Electron., vol. 57, no. 6, pp. 2187-2190, Jun. 2010.

[11] J. Zhang, D. D.-C. Lu, and T. Sun, "Flyback-based single-stage powerfactor- correction scheme with time-multiplexing control," IEEE Trans. Ind. Electron., vol. 57, no. 3, pp. 1041-1049, Mar. 2010.

[12] H. S. Ribeiro and B. V. Borges, "New optimized full-bridge single-stage ac/dc converters," IEEE Trans. Ind. Electron., vol. 58, no. 6, pp. 2397-2409, Jun. 2011.

[13] H. M. Suraywanshi, M. R. Ramteke, K. L. Thakre, and V. B. Borghate, "Unity-power-factor operation of three phase ac-dc soft switched converter based on boost active clamp topology in modular approach," IEEE Trans. Power Electron., vol. 23, no. 1, pp. 229-236, Jan. 2008.

[14] U. Kamnarn and V. Chunkag, "Analysis and design of a modular threephase ac-to-dc converter using CUK rectifier module with nearly unity power factor and fast dynamic response," IEEE Trans. Power Elec., vol. 24, no. 8, pp. 2000-2012, Aug. 2009.

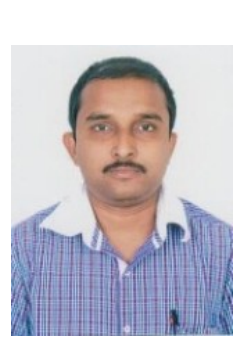

Authors Profile

K Vamshi krishna varma recieved the B.Tech (EEE) in 1994-1998 from S.V.University, Tirupati(A.P)

, M.tech (Power electronics) in 2011 -2013 from PBRVITS Kavali(Nellore Dist) A.P.Worked on reasearch areas Embedded systems, ARM processors, Bluetooth, Wi-fi, VLSI,Power plant simulators, SCADA in various Multinational companies (TI Israel, Access company LTD Japan, Samsung) from 1998 to 2011.currently working as Asst professor in EEE department , Training \& placement officer in Geethanjali Institute of Science \& Technology, Gangavaram(Nellore Dist)

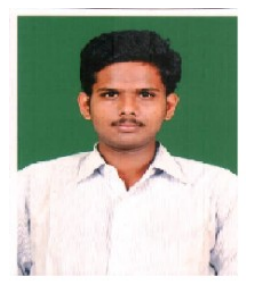

Vemana Arun sai pursuing B.Tech final-semester(ECE) from Geethanjali Institute of Science \& Technology Gangavaram(Nellore Dist)

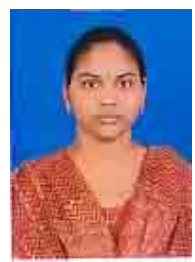

Nasina Jyothirmayi pursuing B.Tech final-semester(ECE) from Geethanjali Institute of Science \& Technology Gangavaram(Nellore Dist)

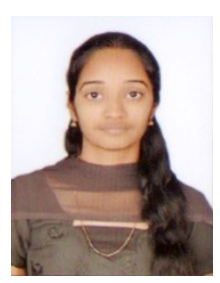

Mohammed Wajidunnisa pursuing B.Tech final-semester(ECE) from Geethanjali Institute of Science \& Technology Gangavaram(Nellore Dist)

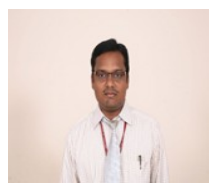

S.SRIDHAR recieved the B.Tech (EEE) in 1995-199 from AEC, Thiruvannamalai, T.N, M.E in Applied Electronics from HCET,chennaiin 1999-2001, Worked as an Associate Professor from Feb-2002 to July 2008 in department of Electrical \& Electronics at Annamacharya Institute of Science \& Technology, Rajampet, Working as an Associate Professor \& H.O.D of EEE in department of Electrical \&Electronics at Geethanjali Institute of Science \& Technology, Nellore since July -2008 to till date 